\title{
Development and oviposition preferences of field collected Aedes albopictus based on different water characteristics
}

\author{
Nazri Che Dom ${ }^{\text {a, b, }}{ }^{,}$, Megat Azman Megat Mokhtar ${ }^{a}$, Cornellia Tata Australia ${ }^{a}$ \\ ${ }^{a}$ Centre of Environmental Health and Safety, Faculty of Health Science, Universiti Teknologi MARA, 42300 Puncak Alam, Selangor, Malaysia \\ ${ }^{b}$ Integrated Mosquito Research Group (I-MeRGe), Universiti Teknologi MARA, 42300 Puncak Alam, Selangor, Malaysia \\ * Corresponding author: nazricd@salam.uitm.edu.my
}

\section{Article history}

Received 20 March 2018

Revised 5 April 2018

Accepted 8 May 2018

Published Online 4 February 2018

\begin{abstract}
Aedes species are rapidly adapting to environmental changes which subsequently changing the preferences for their breeding. In the present study, evaluation of the larval development and oviposition preferences of field collected Aedes albopictus was carried out based on different water characteristic. The eggs of Ae. albopictus and the water samples were collected in UiTM Puncak Alam areas. The types of water samples used in this study were (i) distilled water $\left(\mathrm{WT}_{1}\right)$, (ii) seasoned tap water $\left(\mathrm{WT}_{2}\right.$ ), (iii) pond water $\left(\mathrm{WT}_{3}\right)$, and (iv) drain water $\left(\mathrm{WT}_{4}\right)$. Each types of water was sampled and tested by controlling the presence and absence of larvae food in the experiment. Development of immature stages in pond and drain water with the presence of food showed fast growth compared to the other types of water. Hatching rate was observed to be higher in all types of water with the presence of food. Oviposition preferences showed a significant difference between water. The data generated from this study was important as a baseline data in development and oviposition for dengue vector control especially on the possibility and ability of Ae. albopictus to survive in specific water types as breeding sites.
\end{abstract}

Keywords: Aedes albopictus, development, oviposition, water characteristics

\section{INTRODUCTION}

Aedes species are rapidly adapting to environmental changes which subsequently changing the water container preferences for breeding purpose (Chen et al., 2007; Aida et al., 2011; Dom et al., 2013). The larval and pupal of Aedes mosquito are undergoing development in natural (e.g. rock pools, tree hole) and artificial containers? (e.g. water tanks, blocked drains) in the urban and periurban environment (WHO, 2009; Weaver and Reisen, 2010; Kumawat et al., 2014). The adaptation of the oviposition behaviour of Aedes species may be influenced by the types of water they chose, thus leading to the ineffective mosquito control (Lee, 1991; Nazni et al., 2008; Ramasamy et al., 2011; Dom et al., 2016a). Ae. Albopictus, is an outdoor mosquito that is more invasive and thus, exploiting wider range of water containers located far from household (CDC, 2010). The availability of water types in the environment that is germane to the survival, growth, and development of Aedes mosquito is an important component for the adults to selectively choose their breeding sites, making sure their progeny will survive in it (Rao et al., 2011; Reiskind et al., 2012; Madzlan et al., 2018).

The selection of an oviposition site is an essential part of the life history of all mosquito species (Panigrahi et al., 2014). A broad knowledge of the vector's behavior and ecological factors such as physical characteristics of water can point out the site-specific measures, mainly in those areas where they are most susceptible. Besides that, the oviposition habit of these mosquitos is yet to be understood as there are many factors influencing their oviposition preferences. Mosquito's choice in oviposition site can impose important consequences for population regulation that should be taken into account when designing vector control programs. Therefore, it is vital to understand factors affecting the oviposition behavior of Aedes mosquitoes. This study was aimed to evaluate the oviposition behavior of Ae. albopictus based on selected water types and its physical characteristics of the selected water sources, by observing the rate of larval, pupal and following adult emergence in different types of water and the oviposition preferences in response to different types of water.

\section{EXPERIMENTAL}

\section{Experimental design}

This study was consisted of two phases (Phase I: Field Setting; Phase II: Laboratory Setting). In the field setting, the field strain $\left(\mathrm{F}_{0}\right)$ of Ae. albopictus and collection of water samples from different sources were carried out. The experimental study on the larval development in selected water types and oviposition preferences was done in the laboratory setting. Fig. 1 shows the flow of the experimental steps that carried out in this study.

\section{Collection and colonization of Ae.albopictus}

Ovitraps were prepared and placed randomly within the campus areas for the collection of field strain $\left(\mathrm{F}_{0}\right)$ eggs of Aedes mosquito. Then, the collected eggs were taken to the laboratory for hatching, identifying of species and mass rearing of adult Ae. albopictus in 
order to obtain the first generation $\left(F_{1}\right)$ eggs. Prior to that, water samples were collected and brought to Puncak Alam laboratory for analysis. Four types of water were selected in this study namely distilled water $\left(\mathrm{WT}_{1}\right)$, seasoned tap water $\left(\mathrm{WT}_{2}\right)$, pond water $\left(\mathrm{WT}_{3}\right)$ and drain water $\left(\mathrm{WT}_{4}\right)$.

\begin{tabular}{|c|c|c|c|}
\hline $\begin{array}{l}\text { PHASE I: } \\
\text { Field Setting }\end{array}$ & \multicolumn{3}{|c|}{$\begin{array}{c}\text { PHASE II: } \\
\text { Laboratory Setting }\end{array}$} \\
\hline $\begin{array}{l}\text { Step 1: } \\
\text { i. Collection of field } \\
\text { strain }\left(\mathrm{F}_{0}\right) \text { of } A e \text {. } \\
\text { albopictus using } \\
\text { ovitrap. } \\
\text { ii. Collection of water } \\
\text { samples from } \\
\text { different sources. }\end{array}$ & $\begin{array}{c}\text { Step 2: } \\
\text { Physical } \\
\text { characteristic } \\
\text { analysis of } \\
\text { water sample } \\
\text { collection. }\end{array}$ & $\begin{array}{l}\text { Step 3: } \\
\text { Observation } \\
\text { rate of larval } \\
\text { development } \\
\text { to pupal stage } \\
\text { and adult } \\
\text { emergence in } \\
\text { different } \\
\text { water types }\end{array}$ & $\begin{array}{c}\text { Step 4: } \\
\text { Oviposition } \\
\text { preferences of } \\
\text { Ae. albopictus }\end{array}$ \\
\hline
\end{tabular}

Fig. 1 Schematic diagram for research design on development and oviposition of Ae. albopictus based on different water characteristics.

\section{Development and oviposition bioassay of Ae. albopictus}

The physical characteristics $(\mathrm{pH}$, temperature, turbidity, conductivity, TDS, DO, and salinity) of the collected water were carried out. Then, the (F1) eggs were exposed with different types of water (minimum $200 \mathrm{ml}$ ) by controlling the presence and absence of food. Larval development to pupal stage was recorded by observing the numbers of larval and pupal emergence daily and the numbers of adult's emergence (Fig. 2A). Oviposition preferences were also conducted by exposing different water types to 100 adults (50 +males; $50 \overbrace{}^{\lambda}$ females) in a cage (Fig. 2B).

A
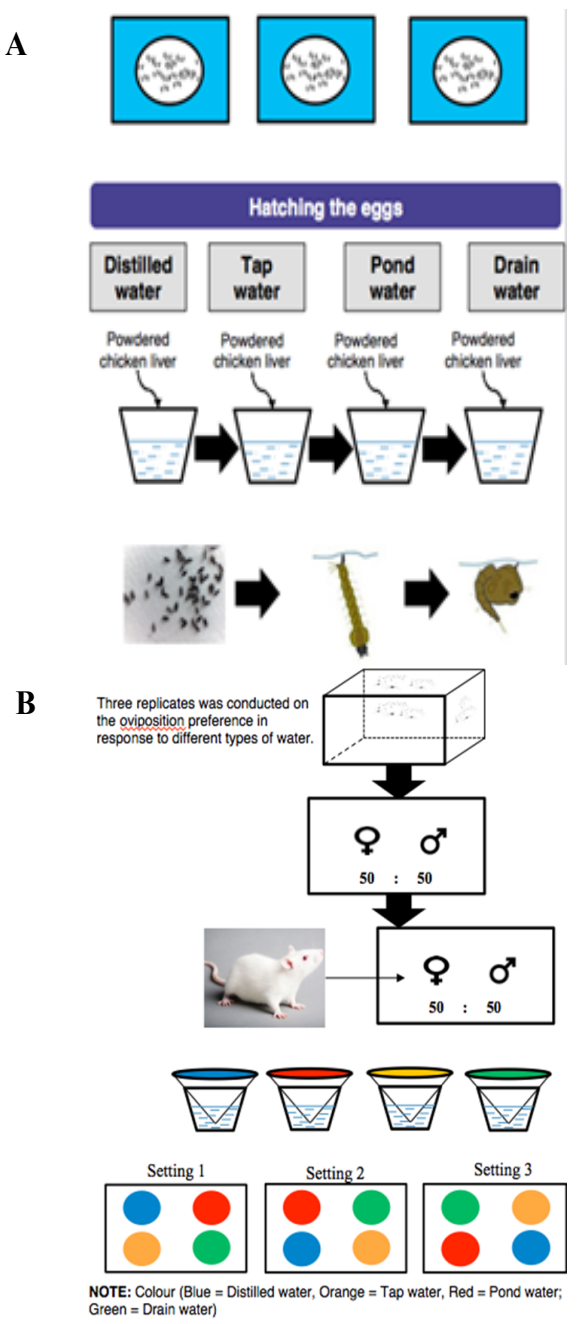

Fig. 2 Schematic diagram for (A) development and (B) oviposition bioassay for $A$ e. albopictus based on different water characteristics.

\section{Data analysis and management}

The data obtained was tabulated and analyzed statistically using the Statistical Package for Social Sciences (SPSS) software for windows, version 21.0. Mean and standard error (SE) were used to summarize the physical characteristic factors of different types of water. Data tabulation was done on the larval and pupa development. Hatching rate was also calculated by counting number of eggs hatched and dividing with the initial number of eggs flooded which was multiplied by 100 . Larval mortality was calculated by dividing the total number of dead larvae by the initial number of larvae (all four instars) multiplied by 100. Both formulas were adapted from Aida et al. (2011). For adult emergence, crude mortality rate was used by counting the number of deaths in a given population, dividing by size of the population and multiplying by 100 (Principles of Infectious Disease Epidemiology). A One-way ANOVA was used to determine the significant differences of oviposition preferences in different water types.

\section{RESULTS AND DISCUSSION}

\section{Identification of physical characteristics of selected water types}

Table 1 summarizes the general profile of the selected water characteristic with the mean and standard error (SE) for each water types. Pond water $\left(\mathrm{WT}_{3}\right)$ recorded the highest water temperature $\left(28.6+0.23^{\circ} \mathrm{C}\right)$, whereas distilled water $\left(\mathrm{WT}_{2}\right)$ exhibited the lowest temperature reading of $26.03+0.03{ }^{\circ} \mathrm{C}$. Distilled water $\left(\mathrm{WT}_{1}\right)$ and seasoned tap water $\left(\mathrm{WT}_{2}\right)$ showed clear turbidity, while pond water $\left(\mathrm{WT}_{3}\right)$ observed to be the most turbid $(37.5 \pm 0.17 \mathrm{NTU})$. As for the $\mathrm{pH}$, the measurement range could be seen to increase from acidic to neutral in distilled water $(\mathrm{pH}: 6.12+0.07)$, drain water $(\mathrm{pH}$ : $6.41 \pm 0.00)$, seasoned tap water $(\mathrm{pH}: 6.70 \pm 0.05)$ and pond water $(\mathrm{pH}$ : 7.10 \pm 0.02$)$. The conductivity $(\mu \mathrm{s})$ and $\overline{\mathrm{TDS}}(\mathrm{mg} / \mathrm{l})$ showed a high measurement in both $\mathrm{WT}_{2}$ and $\mathrm{WT}_{4}$. Dissolved oxygen (DO) $(\mathrm{mg} / \mathrm{l})$ measurement was within the optimum value ranging from $2.31+0.06$ to $3.03+0.00$. Other than that, both $\mathrm{WT}_{1}$ and $\mathrm{WT}_{3}$ have zero measurement for salinity (\%), while $\mathrm{WT}_{2}$ and $\mathrm{WT}_{4}$ recorded to have a value of $0.1+0.00$ and $0.4 \pm 0.00$ respectively.

Table 1 General profile of collected water characteristics.

\begin{tabular}{lcccc}
\hline \multirow{2}{*}{$\begin{array}{c}\text { Physical } \\
\text { parameter }\end{array}$} & \multicolumn{4}{c}{ Water types } \\
\cline { 2 - 5 } & $\mathbf{W T}_{1}$ & $\mathbf{W T}_{2}$ & $\mathbf{W T}_{3}$ & $\mathbf{W T}_{4}$ \\
\hline Temp $\left({ }^{\circ} \mathrm{C}\right)$ & $26.03 \pm$ & $24.30 \pm$ & $28.6 \pm 0.23$ & $26.6 \pm 0.31$ \\
& 0.03 & 0.00 & & \\
Turbidity & $0.00 \pm 0.00$ & $0.00 \pm 0.00$ & $37.5 \pm 0.17$ & $35.9 \pm 0.29$ \\
$\mathrm{pH}$ & $6.12 \pm 0.07$ & $6.70 \pm 0.05$ & $7.10 \pm 0.02$ & $6.41 \pm 0.00$ \\
$\mathrm{Cond}(\mu \mathrm{s})$ & $2.10 \pm 0.58$ & $137.5 \pm$ & $80.8 \pm 4.22$ & $833 \pm 2.88$ \\
& & 5.93 & & \\
$\mathrm{TDS}(\mathrm{mg} / \mathrm{L})$ & $1.00 \pm 0.00$ & $65 \pm 3.00$ & $38 \pm 2.00$ & $398 \pm 4.10$ \\
$\mathrm{DO}(\mathrm{mg} / \mathrm{L})$ & $3.03 \pm 0.00$ & $2.92 \pm 0.01$ & $2.31 \pm 0.06$ & $2.65 \pm 0.04$ \\
Salinity $(\%)$ & $0.0 \pm 0.00$ & $0.1 \pm 0.00$ & $0.0 \pm 0.00$ & $0.4 \pm 0.00$ \\
\hline Note: $\mathrm{WT}_{1}$ - Distilled water, $\mathrm{WT}_{2}-$ Seasoned tap water, $\mathrm{WT}_{3}-$ Pond \\
water, $\mathrm{WT}_{4}$ - Drain water.
\end{tabular}

For each parameters, a distribution order could be used to arrange the water characteristics based on the mean and standard error (SE), starting from the highest to the lowest readings. The distribution was shown in Table 2. From the distribution pattern, it could be seen that pond water $\left(\mathrm{WT}_{3}\right)$ recorded the highest temperature $\left({ }^{\circ} \mathrm{C}\right), \mathrm{pH}$ and turbidity (NTU) in a descending order. This order was also shown by drain water $\left(\mathrm{WT}_{4}\right)$ for conductivity $(\mu \mathrm{s})$, total dissolved solid (TDS) and salinity. On the other hand, distilled water $\left(\mathrm{WT}_{1}\right)$ was observed to be at the lowest rank for $\mathrm{pH}$, conductivity and TDS compared to the other water types, while pond water $\left(\mathrm{WT}_{3}\right)$ was ranked the lowest for dissolved oxygen (DO) and salinity. 
Table 2 Distribution of physical characteristics of collected water.

\begin{tabular}{ll}
\hline $\begin{array}{l}\text { Physical } \\
\text { parameter }\end{array}$ & \multicolumn{1}{c}{ Distribution } \\
\hline Temp $\left({ }^{\circ} \mathrm{C}\right)$ & $\mathrm{WT}_{3}>\mathrm{WT}_{4}>\mathrm{WT}_{1}>\mathrm{WT}_{2}$ \\
Turbidity & $\mathrm{WT}_{3}>\mathrm{WT}_{4}>\mathrm{WT}_{1}>\mathrm{WT}_{2}$ \\
$\mathrm{pH}$ & $\mathrm{WT}_{3}>\mathrm{WT}_{2}>\mathrm{WT}_{4}>\mathrm{WT}_{1}$ \\
Cond $(\mu \mathrm{s})$ & $\mathrm{WT}_{4}>\mathrm{WT}_{2}>\mathrm{WT}_{3}>\mathrm{WT}_{1}$ \\
$\mathrm{TDS}(\mathrm{mg} / \mathrm{L})$ & $\mathrm{WT}_{4}>\mathrm{WT}_{2}>\mathrm{WT}_{3}>\mathrm{WT}_{1}$ \\
$\mathrm{DO}(\mathrm{mg} / \mathrm{L})$ & $\mathrm{WT}_{1}>\mathrm{WT}_{2}>\mathrm{WT}_{4}>\mathrm{WT}_{3}$ \\
Salinity $(\%)$ & $\mathrm{WT}_{4}>\mathrm{WT}_{2}>\mathrm{WT}_{1}>\mathrm{WT}_{3}$ \\
\hline
\end{tabular}

Note: > - more than.

\section{Determination of larval development rate to pupal stage} and adult emergence in each water samples

The numbers of adult emergence were recorded daily in order to see the duration for development of pupal stage into the adult stage. The red dotted lines were used to mark the approximate days of hatching $(h)$ and adult emergence $(a)$. The emergence of adults that exposed with distilled water $\left(\mathrm{WT}_{1}\right)$ and seasoned tap water $\left(\mathrm{WT}_{2}\right)$ showed a longer development period to be emerged as compared with both pond water $\left(\mathrm{WT}_{3}\right)$ and drain water $\left(\mathrm{WT}_{4}\right)$ that recorded less than 2 weeks for the adult mosquitoes to emerge from the pupal stage. The pattern of adult emergence for drain water $\left(\mathrm{WT}_{4}\right)$ recorded the shortest development period (Fig. 3A).

Immature stages and numbers of emerged adults were also being recorded and measured by calculated their hatching rate (\%) and mortality rate $(\%)$ respectively. Fig. 3B tabulate the hatching rate and mortality rate of the immature stages of Ae. albopictus. In general, the hatching rate for all types of was high (96-99\%). In terms of mortality rate of larvae, distilled water and pond water was recorded with high mortality rate as compared to seasoned tap water and drain water.

In Fig. 3C, the emergence of adults $\left(\mathrm{F}_{2}\right)$ was recorded and male-to-female ratio and mortality rate were also measured. The dispersal of male $(+\circ)$ and female $(\overbrace{}^{\lambda})$ Ae. albopictus were identified in numerical and percentage. From the result shown, distilled water has the highest number of survived adult with 90 adults (Male: 53.33\%; Female: $46.67 \%$ ), followed by pond water with a cumulative number of 89 survived adults (Male: $40.45 \%$; Female: $59.55 \%$ ). Drain water recorded a total of 84 survived adults (Male: 41.67\%; Female: $58.33 \%$ ), while seasoned tap water has 87 survived adults (Male: $32.18 \%$; Female: $67.82 \%$ ). From the number of survived adults recorded, the mortality rate in $\mathrm{WT}_{1}, \mathrm{WT}_{2}, \mathrm{WT}_{3}$ and $\mathrm{WT}_{4}$ were $1.11 \%$, $8.05 \%, 2.25 \%$ and $15.48 \%$ respectively.

\section{Determination of oviposition preferences in response to different water types}

Three replicates were conducted on the oviposition preference in response to different types of water. The total number of eggs laid was measured. Statistical analysis of One-way ANOVA was conducted to determine the significant difference between different types of water. Table 3 shows the total number of eggs laid by the female mosquitoes in each selected water types. It could be seen that, drain water $\left(\mathrm{WT}_{4}\right)$ $(1542.67+448.43)$ has the highest number of eggs laid, while distilled water $\left(\mathrm{WT}_{1}\right)$ has the least number of eggs laid with a value of $85.00+52.00$. From the findings, there was a significant differences in oviposition preferences between the selected types of water.

The quality of water is an essential determinant for female mosquitoes to lay their eggs and complete their development into adult stages (Piyaratnea et al. 2005; Dom et al., 2016b). The result of this study indicated that, the water temperature for each water types was suitable for Ae. albopictus. This finding was in good agreement with the ideas of Rohani et al. (2014), who suggested that breeding activity was highest for both dengue vectors in breeding sites with temperature between 25 and $30^{\circ} \mathrm{C}$. The value of $\mathrm{pH}$ for different types of water showed the normal range between 6-7. The finding of this assessment was also is in accordance with study conducted by Amarasinghe and Dalpadado's (2014), who stated Aedes species might survive within a very narrow $\mathrm{pH}$ range from 6-8. From the physical profile of the water, it could be concluded that the all water types were within the optimal condition for breeding site.

A.

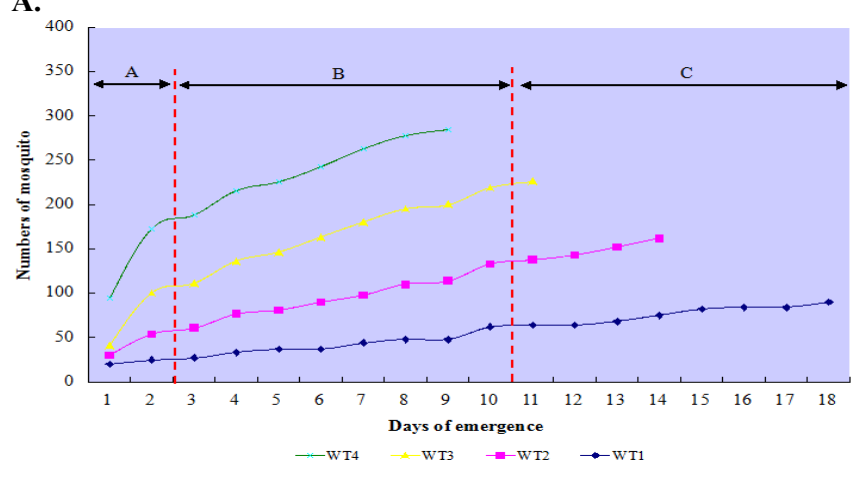

B.

\begin{tabular}{lccccc}
\hline $\begin{array}{c}\text { Bypes } \\
\text { of } \\
\text { water }\end{array}$ & $\begin{array}{c}\text { Eggs } \\
\text { (a) }\end{array}$ & $\begin{array}{c}\text { Larvae } \\
\text { (b) }\end{array}$ & $\begin{array}{c}\text { Pupae } \\
\text { (c) }\end{array}$ & $\begin{array}{c}\text { Hatching } \\
\text { Rate (\%) } \\
{[(\mathbf{b} / \mathbf{a}) \times 100]}\end{array}$ & $\begin{array}{c}\text { Mortality } \\
\text { Rate (\%) } \\
{[(\mathbf{b}-\mathbf{c}) / \mathbf{b}} \\
\mathbf{x ~ 1 0 0 ]}\end{array}$ \\
\hline $\mathbf{W T}_{1}$ & 100 & 98 & 91 & 98 & 7.14 \\
$\mathbf{W T}_{2}$ & 100 & 96 & 94 & 96 & 2.08 \\
$\mathbf{W T}_{3}$ & 100 & 99 & 91 & 99 & 8.08 \\
$\mathbf{W T}_{4}$ & 100 & 97 & 97 & 97 & 0.00 \\
\hline
\end{tabular}

\begin{tabular}{|c|c|c|c|c|c|c|}
\hline \multirow{2}{*}{$\begin{array}{l}\text { Types } \\
\text { of } \\
\text { water }\end{array}$} & \multirow[t]{2}{*}{$\begin{array}{l}\text { No of } \\
\text { pupae }\end{array}$} & \multicolumn{3}{|c|}{$\begin{array}{c}\text { No. of survived adult } \\
\left(F_{2}\right)\end{array}$} & \multirow{2}{*}{$\begin{array}{c}\text { Male- } \\
\text { Female } \\
\text { Ratio }\end{array}$} & \multirow{2}{*}{$\begin{array}{c}\text { Mortality } \\
\text { Rate (\%) } \\
{[(a-b) / b} \\
\text { x100] }\end{array}$} \\
\hline & & $\begin{array}{c}\text { Male } \\
+ \\
+\end{array}$ & $\underset{\hat{\delta}}{\text { Female }}$ & $\begin{array}{l}\text { Total } \\
\text { (b) }\end{array}$ & & \\
\hline $\mathbf{W T}_{1}$ & 91 & 48 & 42 & 90 & $1.1: 1.0$ & 1.11 \\
\hline $\mathrm{WT}_{2}$ & 94 & 28 & 59 & 87 & $1: 2.1$ & 8.05 \\
\hline $\mathbf{W T}_{3}$ & 97 & 36 & 53 & 89 & 1:1.5 & 2.25 \\
\hline $\mathbf{W T}_{4}$ & 91 & 35 & 49 & 84 & $1: 1.4$ & 15.48 \\
\hline
\end{tabular}

Fig. 3 Larval development to pupal stages and adult emergence in different types of water: (A) Pattern of hatching and adult emergence; (B) Mortality rate of immatures stage and (C) Emergence and mortality rate of adult mosquitoes. Note: $\mathrm{WT}_{1}$ : Distilled water; $\mathrm{WT}_{2}$ : Seasoned tap water; $\mathrm{WT}_{3}$ : Pond water and $\mathrm{WT}_{4}$ : Drain water.

Table 3 Oviposition preferences in response to different water types.

\begin{tabular}{cccc}
\hline Water types & $\begin{array}{c}\text { No of eggs } \\
\text { collected }\end{array}$ & F-value & P-value $^{*}$ \\
\hline $\mathbf{W T}_{1}$ & $85.00 \pm 52.00$ & 10.342 & 0.004 \\
$\mathbf{W T}_{2}$ & $101.00 \pm 27.59$ & & \\
$\mathbf{W T}_{3}$ & $75.33 \pm 18.42$ & & \\
$\mathbf{W T}_{4}$ & $1542.67 \pm 448.43$ & & \\
\hline
\end{tabular}

* Note: $p$-value generated from oneway ANOVA analysis

In this study, the growth of the larvae was indeed faster with the presence of food supplies. Gomes et al. (1995) documented that the growth of mosquito at immature stages was depended on food supply. Eggs of Aedes mosquito are sensitive to changes in water temperature, 
thus the temperature and relative humidity were maintained at $28+2$ ${ }^{\circ} \mathrm{C}$ and $75 \%$ to $85 \%$, accordingly. Besides that, the hatching rate of Aedes eggs was also depended on the temperature and relative humidity as mosquito larval stages are poikilothermic (Dickerson 2007). Naturvardsverket (2007) emphasized that, low DO concentrations $(<3 \mathrm{mg} / \mathrm{l})$ was difficult for many species or aquatic organisms to survive, but the critical value were varies among species in terms of optimal concentration and tolerance limits (Clark et al., 2004; Madzlan et al., 2016). For this reason, the adult mortality rate was low, and could be due to the water profile which was conducive environment for development of immature stages.

Oyewole et al. (2009) emphasized that, mosquito exploited almost all types of aquatic habitats for breeding, and the prevailing physicochemical parameters in these habitats were vital factors for development and survival of mosquito. In the present experiment, the maximum number of eggs laid by the females was in drain water followed by seasoned tap water, distilled water, and pond water. From the findings, there was a significant difference $(p$-value $<0.05)$ in the oviposition preferences between the selected water types. Other medium such as distilled water, season tap water and pond were found to have the least number of eggs laid. This could be due to the behaviour called skip-oviposition that exhibited by the female mosquitoes. Colton et al. (2003) described this behaviour as the distribution of egg-laying by female mosquitoes in multiple waterfilled containers rather than a single clutch in one container.

\section{CONCLUSION}

Knowledge on development and oviposition is important in dengue vector control especially on the possibility and ability of $\mathrm{Ae}$. albopictus to survive in specific water types. Water quality of the breeding site is a critical factor for the female mosquito to oviposit because female mosquito chooses oviposition sites by a combination of visual and chemical cues. The result of the finding indicated that, all the selected water types were suitable for the development of immature stages, but different in terms of days, thus it could be used as reference in prevention and control approach. Furthermore, a more detail research on the eco-biology, life tables and the duration of the cycle should be carried out on the Aedes mosquito.

\section{ACKNOWLEDGEMENT}

The authors gratefully acknowledge contribution of research funding from Universiti Teknologi MARA (UiTM) (600-IRMI/DANA 5/3LESTARI (0093/2016) and Ministry of Higher Education (MOHE) Malaysia are also duly acknowledge.

\section{REFERENCES}

Aida, H. N., Dieng, H., Ahmad, A. H., Satho, T., Nurita, A. T., Salmah, M. C., Miake, F., Norasmah, B. (2011). The biology and demographic parameters of Aedes albopictus in Northern Peninsular Malaysia. Asian Pacific Journal of Tropical Biomedicine, 1(6), 472-7.

Amarasinghe, L., Dalpadado, D. R. (2014). Vector mosquito diversity and habitat variation in a semi urbanized are of Kelaniya in Sri Lanka. International Journal of Entomological Research, 2(1), 15-21.

Chen, C. D., Nazni, W. A., Seleena, B., Moo, J. Y., Azizah, M., Lee, H. L. (2007). Comparative oviposition preferences of Aedes (Stegomyia) aegypti (L.) to water from storm water drains and seasoned tap water. Medical Entomology Unit, 31, 124-130.

Clark, T. M., Flis, B. J., Remold, S. K. (2004). pH tolerances and regulatory abilities of freshwater and Euryhaline adeline mosquito larvae. Journal of Experimental Biology, 207(13), 2297-2304.

Colton, Y. M., Chadee, D. D., Severson, D. W. (2003). Natural "skip oviposition" of the mosquito Aedes aegypti as evidenced by codominant genetic markers. Medical and Veterinary Entomology, 17(2), 195-201.
Dickerson, C. Z. (2007). The effects of temperature and humidity on the eggs of Aedes aegypti (L.) and Aedes albopictus (Skuse) in Texas. Doctoral Dissertation, Texas A\&M University.

Dom, N. C., Ahmad, A. H., Ismail, R. (2013). Habitat characterization of Aedes sp. breeding in urban hotspot area. Procedia-Social and Behavioral Sciences, 85, 100-109.

Dom, N., Faiz Madzlan, M., Nadira Yusoff, S. N., Hassan Ahmad, A., Ismail, R., Nazrina Camalxaman, S. (2016a). Profile distribution of juvenile Aedes species in an urban area of Malaysia. Transactions of The Royal Society of Tropical Medicine and Hygiene, 110(4), 237-245.

Dom, N, Faiz Madzlan, M, Nur, A. H., Misran, N. Water quality characteristics of dengue vectors breeding containers. International Journal of Mosquito Research 3, no. 1 (2016b): 25-9.

Gomes, A. D. C., Gotlieb, S. L., Marques, C. D. A., Paula, M. B., Marques G. R. (1995). Duration of larval and pupal development stages of Aedes albopictus in natural and artificial containers. Revista de Saude Publica, 29(1), 15-9

Oyewole, O. Momoh, O. O., Anyasor, G. N., Ogunnowo, A. A., Ibidapo, C. A., Oduola, O. A., Obansa, J. B., Awolola, T. S.. (2009) Physicochemical characteristics of Anopheles breeding sites: Impact on fecundity and progeny development. African Journal of Environmental Science and Technology, 3(12), 447-452.

Kumawat, R., Singh, K. V., Bansal, S. K., Singh, H. (2014). Use of different coloured ovitraps in the surveillance of Aedes mosquitoes in an AridUrban Area of Western Rajasthan. Journal of Vector Borne Diseases, 51, 320-326.

Lampbert, W., Sommer, U. ( $2^{\text {nd }}$ Ed.). (2007). Limnoecology: The ecology of lakes and streams. Journal of Plankton Research, 30(4), 489-490.

Lee, S. J. (1991). Major factors affecting mosquito oviposition. Chinese Journal of Entomology, 6, 23-35.

Madzlan, F., Dom, N. C., Tiong, C. S., Zakaria, N. (2016). Breeding characteristics of aedes mosquitoes in dengue risk area. Procedia-Social and Behavioral Sciences, 234, 164-172.

Madzlan, F., Dom, N. C., Zakaria, N., Hasnan, S. N. A., Tiong, C. S., Camalxaman, S. N. (2018). Profiling of dengue vectors breeding habitat at urban residential areas in Shah Alam, Malaysia. Serangga, 22(2), 185 216.

Naturvardsverket. (2007). Assessment Criteria for Lakes and Rivers.

Retrieved fromhttps://www.naturvardsverket.se/Documents/publikationer/6200148-3.pdf

Panigrahi, S. K., Barik, T. K., Mohanty, S., Tripathy, N. K. (2014). Laboratory evaluation of oviposition behavior of field collected Aedes mosquitoes. Journal of Insects, 2014, Article ID 207489.

Piyaratnea, Maldeniya, K., Amerasinghe, F., Amerasinghe, P., Konradsen, F. (2005). Physico-chemical characteristics of Anopheles culicifacies and Anopheles varuna breeding water an a dry zone stream in Sri Lanka. Journal of Vector Borne Diseases, 42(2), 61-67.

Ramasamy, R., Surendran, S. N., Jude, P. J., Dharshini, S., Vinobaba, M. (2011). Larval development of Aedes aegypti and Aedes albopictus in Peri-Urban Brackish water and its implications for transmission of arboviral diseases. PLoS Neglected Tropical Diseases, 5(11), e1369.

Rao, B. B., Harukumar, P. S., Jayakrishnan, T., George, B. (2011). Characteristics of Aedes ( STEGOMYIA ) Albopictus Skuse (DIPTERA : CULICIDAE ). Breeding sites. Southeast Asian Journal of Tropical Medicine and Public Health, 42(5), 1077-1082.

Reiskind, M. H., Zarrabi, A. A., Zarrabi, A. L. I. A. (2012). Water surface area and depth determine oviposition choice in Aedes albopictus (Diptera: Culicidae) Journal of Medical Entomolgy, 49(1), 71-76.

Rohani, A., Azahary, A. R. A., Malinda, M., Zurainee, M. N., Rozilawati, H., Wan Najdah, W. M. A., Lee, H. L. (2014). Eco-virological survey of Aedes mosquito larvae in selected dengue outbreak areas in Malaysia. Journal of Vector Borne Disease, 51, 327-332.

Walton, W. E. (1990). Distribution of Culextarsalis larvae in a freshwater Marsh in Orange County, California. Journal of The American Mosquito Control Association, 6, 539-543.

Weaver, S. C., Reisen, W. K. (2010). Present and future arbovirus threats. Antiviral Research, 85, 328-345.

World Health Organization (Ed.). (2009). Dengue Guidelines For Diagnosis, Treatment, Prevention and Control.

Retrieved from http://www.who.int/tdr/publications/documents/denguediagnosis.pdf. 